\title{
DC-SIGN targets amphotericin B-loaded liposomes to diverse pathogenic fungi
}

\author{
Suresh Ambati ${ }^{*} \mathbb{D}$, Tuyetnhu Pham² ${ }^{2}$ Zachary A. Lewis ${ }^{2}$, Xiaorong Lin² and Richard B. Meagher ${ }^{1}$
}

\begin{abstract}
Background: Life-threatening invasive fungal infections are treated with antifungal drugs such as Amphotericin $B$ $(\mathrm{AmB})$ loaded liposomes. Our goal herein was to show that targeting liposomal AmB to fungal cells with the C-type lectin pathogen recognition receptor DC-SIGN improves antifungal activity. DC-SIGN binds variously crosslinked mannose-rich and fucosylated glycans and lipomannans that are expressed by helminth, protist, fungal, bacterial and viral pathogens including three of the most life-threatening fungi, Aspergillus fumigatus, Candida albicans and Cryptococcus neoformans. Ligand recognition by human DC-SIGN is provided by a carbohydrate recognition domain (CRD) linked to the membrane transit and signaling sequences. Different combinations of the eight neck repeats (NR1 to NR8) expressed in different protein isoforms may alter the orientation of the CRD to enhance its binding to different glycans.
\end{abstract}

Results: We prepared two recombinant isoforms combining the CRD with NR1 and NR2 in isoform DCS12 and with NR7 and NR8 in isoform DCS78 and coupled them to a lipid carrier. These constructs were inserted into the membrane of pegylated AmB loaded liposomes AmB-LLs to produce DCS12-AmB-LLs and DCS78-AmB-LLs. Relative to AmB-LLs and Bovine Serum Albumin coated BSA-AmB-LLs, DCS12-AmB-LLs and DCS78-AmB-LLs bound more efficiently to the exopolysaccharide matrices produced by A. fumigatus, C. albicans and C. neoformans in vitro, with DCS12-AmB-LLs performing better than DCS78-AmB-LLs. DCS12-AmB-LLs inhibited and/or killed all three species in vitro significantly better than AmB-LLs or BSA-AmB-LLs. In mouse models of invasive candidiasis and pulmonary aspergillosis, one low dose of DCS12-AmB-LLs significantly reduced the fungal burden in the kidneys and lungs, respectively, several-fold relative to AmB-LLs.

Conclusions: DC-SIGN's CRD specifically targeted antifungal liposomes to three highly evolutionarily diverse pathogenic fungi and enhanced the antifungal efficacy of liposomal AmB both in vitro and in vivo. Targeting significantly reduced the effective dose of antifungal drug, which may reduce drug toxicity, be effective in overcoming dose dependent drug resistance, and more effectively kill persister cells. In addition to fungi, DC-SIGN targeting of liposomal packaged anti-infectives have the potential to alter treatment paradigms for a wide variety of pathogens from different kingdoms including protozoans, helminths, bacteria, and viruses which express its cognate ligands.

Keywords: C-type lectins, CD209, Dendritic Cell-Specific ICAM-3-Grabbing Non-Integrin 1, Targeted antimicrobial drugs, Liposomes, Pathogenic fungi, DectiSomes

*Correspondence: asuresh@uga.edu

${ }^{1}$ Department of Genetics, University of Georgia, Athens, GA 30602, USA

Full list of author information is available at the end of the article

\begin{abstract}
Background
DectiSomes are lipid nanoparticles carrying an antiinfective and coated with a protein that targets them to a pathogen $[1,2]$. The goal in the design of DectiSomes is to increase the local drug concentration at the pathogen's surface and reduce the drug concentration
\end{abstract}

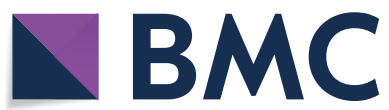

(c) The Author(s) 2021. Open Access This article is licensed under a Creative Commons Attribution 4.0 International License, which permits use, sharing, adaptation, distribution and reproduction in any medium or format, as long as you give appropriate credit to the original author(s) and the source, provide a link to the Creative Commons licence, and indicate if changes were made. The images or other third party material in this article are included in the article's Creative Commons licence, unless indicated otherwise in a credit line to the material. If material is not included in the article's Creative Commons licence and your intended use is not permitted by statutory regulation or exceeds the permitted use, you will need to obtain permission directly from the copyright holder. To view a copy of this licence, visit http://creativecommons.org/licenses/by/4.0/. The Creative Commons Public Domain Dedication waiver (http://creativeco mmons.org/publicdomain/zero/1.0/) applies to the data made available in this article, unless otherwise stated in a credit line to the data. 
delivered to host cells [1]. We've previously shown that two classes of DectiSomes, Amphotericin B (AmB) Loaded Liposomes (AmB-LLs) coated with either of two C-type lectin pathogen receptors Dectin-1 or Dectin-2 are concentrated on fungal pathogens and have improved antifungal efficacy. In particular, the carbohydrate recognition domains (CRDs) of these two proteins bind fungal oligoglucans and oligomannans, respectively. Dectin targeted AmB and Anidulafungin loaded liposomes (e.g., DEC1-AmB-LLs and DEC2-AmB-LLs) are order(s) of magnitude more effective than AmB-LLs at binding and killing Aspergillus fumigatus, Candida albicans, and/or Cryptococcus neoformans in vitro [24]. DEC2-AmB-LLs are dramatically more effectively at controlling infections in mouse models of pulmonary aspergillosis [1,5] and invasive candidiasis [2] than untargeted AmB-LLs. The Dectins recognize most fungal pathogens [6] and many non-fungal pathogens [7]. We wished to expand our exploration to other potential targeting proteins that recognized fungal pathogens and an even wider variety of non-fungal pathogens.

Human DC-SIGN (a.k.a., CD-SIGN, ICAM-3) is C-type lectin pathogen receptor encoded by the CD209 gene. Its CRD binds variously crosslinked mannoserich and fucosylated glycans (e.g., the Lewis ${ }^{X}$ trisaccharide), and lipomannans often found in protein conjugates [8-11]. Consequently, DC-SIGN's CRD recognizes cognate glycans in diverse fungal [6], viral [12], helminth [13], protist [14], and bacterial [15] pathogens, and thus has the potential for liberal pathogen targeting of liposomes. DC-SIGN is expressed by Antigen-Presenting Cells and a few other cell types. In dendritic cells, when DC-SIGN's extracellular CRD binds to its cognate ligands, its intracellular domain signals both innate and adaptive immune responses to infection $[6,16,17]$. Because mouse genomes encode eight DC-SIGN homologs, but no clearly defined ortholog of human DC-SIGN [18], we initiated this project with human DC-SIGN, even though we will test it here in mouse disease models.

Among various fungal pathogens recognized by DCSIGN [6], Aspergillus spp., Candida spp., and Cryptococcus spp., cause a majority of global life-threatening invasive fungal infections and hundreds of thousands of deaths annually $[19,20]$. These three genera partially represent the extreme diversity in the fungal kingdom, because they diverged from common ancestors approximately 0.8 to 1.3 billion years ago [21]. These fungi are responsible for approximately 4.5 billion dollars in U.S. medical costs annually [22], further supporting their importance as models for our study. Herein, we examine DC-SIGN's targeting of liposomes to representatives of these three fungal genera.
Full-length human DC-SIGN (NCBI accession \# Q9NNX6.1) is a 404 amino acid (aa) long protein (Fig. 1). The protein includes 8 neck repeats NR1 to NR8 (each 21 to 23 aa long) linked to its C-terminal CRD (151 aa) [23, 24] (Fig. 1a, Additional file 1: Fig. S1a). Alternate splicing produces a number of DC-SIGN isoforms that lack from one to seven of the eight NRs, but all isoforms retain the CRD [25]. The various isoforms of DC-SIGN float in the cell membrane as monomers, dimers, and tetramers and all three forms bind glycan ligands [24, 26-29]. Different combinations of NRs stabilize distinct homo-multimers which presumably have higher avidity than monomers and are proposed to provide alternate membrane positioning that may influence the specificity of binding to diverse glycans expressed by various pathogens [27, 30]. Herein we tested the ability of two recombinant isoforms of DC-SIGN to selectively target antifungal drug loaded liposomes to fungal pathogens. Liposomes targeted by one isoform in particular showed significantly enhanced binding and antifungal activity relative to untargeted antifungal liposomes.

\section{Results \\ The design of DC-SIGN targeted liposomes}

We engineered two recombinant isoforms of human DC-SIGN. Each isoform contains the CRD and two NRs (Fig. 1b, 1c, Additional file 2: Fig. S1b, c) and we produced them in mg quantities. They each lack the signal peptide domain (SP), signaling domain (SD) and transmembrane domain (TM) found in the native human DC-SIGN protein (Fig. 1a). The DCS78 (24.2 kDa) construct has the proximal NR7 and NR8 fused to the CRD. NR7 and NR8 are retained in most known mRNA splice variants [25] and all known human genetic polymorphisms [30], but neither splice variants nor polymorphic isoforms have been reported with just these two repeats alone. Hence, this is not a known native isoform. A recombinant isoform with only NR7 and NR8 fused to the CRD is known to form homodimers [30], but its glycan binding properties are unknown. The DCS12 $(24.9 \mathrm{kDa})$ construct has distal NR1 and NR2 fused to the CRD (Fig. 1c). The design of DCS12 is based on a known human splice-variant encoded isoform of DC-SIGN that efficiently forms functional homotetramers and recognizes C. albicans cells, mannan-agarose, and $N$-acetyl galactosamineagarose [25]. The DCS12 and DCS78 peptides were coupled to a lipid carrier and inserted into the membrane of amphotericin B loaded pegylated liposomes, AmB-LLs, to make DCS12-AmB-LLs and DCS78-AmB-LLs, respectively. The two modified DC-SIGN peptides are predicted to float in the liposome membrane and form active homomultimers that bind fungal glycans as modeled in Fig. 1d. We also coupled Bovine Serum Albumin (BSA, 


\begin{tabular}{|c|c|c|c|c|c|c|c|c|}
\hline $\mathrm{NH}_{3}{ }^{+}$ & $\mathrm{SP}$ & SD & TM & \begin{tabular}{l|l|l}
1 & 2 & 3
\end{tabular} & \begin{tabular}{l|l|l}
4 & 5 & 6
\end{tabular} & 78 & CRD & $\mathrm{COO}^{-}$ \\
\hline \multicolumn{9}{|c|}{ b. DCS78 223 a.a. } \\
\hline $\mathrm{NH}_{3}{ }^{+}$ & $\mathrm{MH}_{6} \mathrm{~V}$ & $(G S)_{2} G$ & DDDDK & KGK' & 5) $)_{2} G_{\text {. }}$ & 78 & CRD & $\mathrm{COO}$ \\
\hline \multicolumn{9}{|c|}{ c. DCS12 221 a.a. } \\
\hline $\mathrm{NH}_{3}{ }^{+}$ & $\mathrm{MH}_{6} \mathrm{~V}$ & $(\mathrm{GS})_{2} \mathrm{G}$ & DDDDK & KGK & $(\mathrm{GS})_{2} \mathrm{G}$ & \begin{tabular}{|l|l}
1 & 2 \\
\end{tabular} & CRD & $\mathrm{coo}$ \\
\hline
\end{tabular}

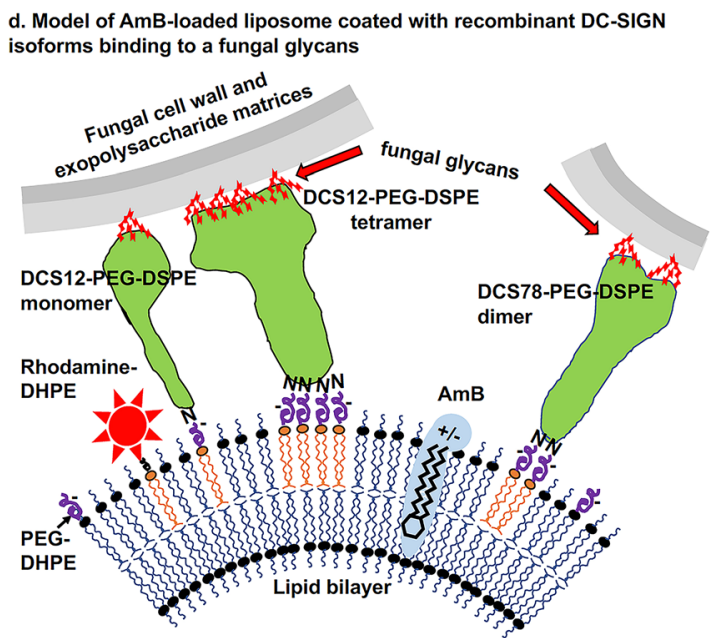

Fig. 1 Recombinant human DC-SIGN isoforms were expressed, purified, and used to target drug loaded liposomes to fungal glycans. a Full length native human DC-SIGN is composed of a SP (Signal Peptide domain), SD (Signaling Domain), TM (Transmembrane domain), eight neck repeats (NRs), and a carbohydrate recognition domain (CRD). We expressed and purified two truncated recombinant isoforms of human DC-SIGN each with two NRs fused to the CRD (b) DCS78 contains NRs 7 and 8. c DCS12 contains NRs 1 and 2 and each contained a KGK sequence for coupling to a free $\mathrm{K}$ residue. Both DC-SIGN isoforms were used to target drug loaded liposomes. d Model of a targeted liposome. DCS12 and DCS78 monomers and predicted homodimers, and/or homotetramers (green irregular structures) have their shapes modeled from crystallographic structures of DC-SIGN monomers and multimers linked to two NRs [23]. They are shown binding to cognate glycans (e.g., red sugar moieties) in the cell walls and exopolysaccharide matrices of fungal cells. DCS12 and DCS78 were coupled to the lipid carrier DSPE-PEG via a lysine amino group (N) in each polypeptide. DHPE-Rhodamine (red star) along with DCS12-PEG-DSPE or DCS78-PEG-DSPE were inserted via their respective lipid moieties, DHPE and DSPE, into the liposomal membrane of amphotericin B loaded pegylated liposomes, AmB-LLs, to make red fluorescent DCS12-AmB-LLs and DCS78-AmB-LL. Each liposome contains approximately 3000 rhodamine molecules, 1500 monomers of a DC-SIGN isoform, and 16,500 AmB molecules [4]. DC-SIGN derived monomers are free to float in the membrane and are predicted to form functional multimers. The various objects in this diagram could not be drawn to the same scale due their extreme size differences. Single letter amino acid coding of particular domains are indicated: $\mathrm{MH}_{6} \mathrm{~V}$ (hexa-histidine $(\mathrm{H})$ tag for affinity purification), $(\mathrm{GS})_{2} \mathrm{G}$ (flexible linkers to improve accessibility to flanking domains), DDDDK (protease processing site for potential removal of multimeric histidine tag), KGK (contains two lysine $(K)$ residues for potential coupling to lipid carrier). Definitions: DSPE (1,2-Distearoyl-sn-glycero-3-phosphoethanol amine), DHPE (1,2-Dihexadecyl-sn-glycero-3-phosphoethanolamine)
$65 \mathrm{kDa}$ ) to the same lipid carrier and constructed BSA coated BSA-AmB-LLs as a protein coated untargeted liposome control [4]. Rhodamine B was inserted quantitatively into the liposome membrane to fluorescently tag all four types of liposomes, AmB-LLs, DCS12-AmBLLs, DCS78-AmB-LLs, and BSA-AmB-LLs. The chemical compositions of all four types of liposomes examined herein and for comparison that of AmBisome ${ }^{\circledR}$ are given in Additional file 1: Table S1.

\section{DCS12 and DCS78 coated liposomes bound to the fungal} exopolysaccharide matrices of three diverse fungal species We examined the ability of DCS12-AmB-LLs and DCS78-AmB-LLs to bind fungal cells in vitro and quantified these results by measuring the relative area of red fluorescent liposome binding to fungal cells as compared to that of AmB-LLs and BSA-AmB-LLs. Representative photographic images of red fluorescent liposomes binding to bright field images of fungal cells in green are presented in Fig. 2. Both DCS12-AmB-LLs and DCS78AmB-LLs bound to what appears to be secreted patches of exopolysaccharide matrix surrounding colonies of $C$. albicans hyphae (Fig. 2a). Respectively, they bound at least 29-fold and 22-fold more strongly than AmB-LLs $\left(\mathrm{P}=9.8 \times 10^{-9}, \mathrm{P}=2.3 \times 10^{-5}\right)$ (Fig. 2b). DCS12-AmB-LLs may have bound slightly more efficiently than DCS78AmB-LLs $(\mathrm{P}=0.08)$. Patches of exopolysaccharide binding appeared more frequent at the periphery of colonies rather than at the center. Respectively, DCS12-AmB-LLs and DCS78-AmB-LLs bound 28-fold $\left(\mathrm{P}=8.9 \times 10^{-11}\right)$ and 6.3-fold $\left(\mathrm{P}=7.3 \times 10^{-5}\right)$ more strongly to patches of exopolysaccharide associated with A. fumigatus hyphae than AmB-LLs (Fig. 2c, d). DCS12-AmB-LLs bound 4.8-fold more strongly than DCS78-AmB-LLs $\left(\mathrm{P}=8.4 \times 10^{-8}\right)$. Respectively, DCS12-AmB-LLs and DCS78-AmB-LLs bound 32-fold $\left(\mathrm{P}=7.9 \times 10^{-7}\right)$ and tenfold $(\mathrm{P}=0.056)$ more strongly to the exopolysaccharide matrix allied with $C$. neoformans cells than AmBLLs (Fig. 2e, f). DCS12-AmB-LLs bound threefold more strongly than DCS78-AmB-LLs $(\mathrm{P}=0.005)$. BSA-AmBLL control liposomes, did not bind noticeably stronger or weaker to any of the three fungal species than AmBLLs, suggesting that simply coating liposomes with protein was not sufficient to enhance or diminish binding. Although we cannot exclude low levels of cell wall binding, neither of the DC-SIGN isoform-targeted liposomes appeared to be strongly associated with fungal cell walls. Because DCS12 coated liposomes bound to all three species more efficiently than DCS78 coated liposomes and represents a native isoform conformation, we focused on DCS12-AmB-LLs in the following experiments examining antifungal activity. 


\section{a. Liposome binding to $C$. albicans}

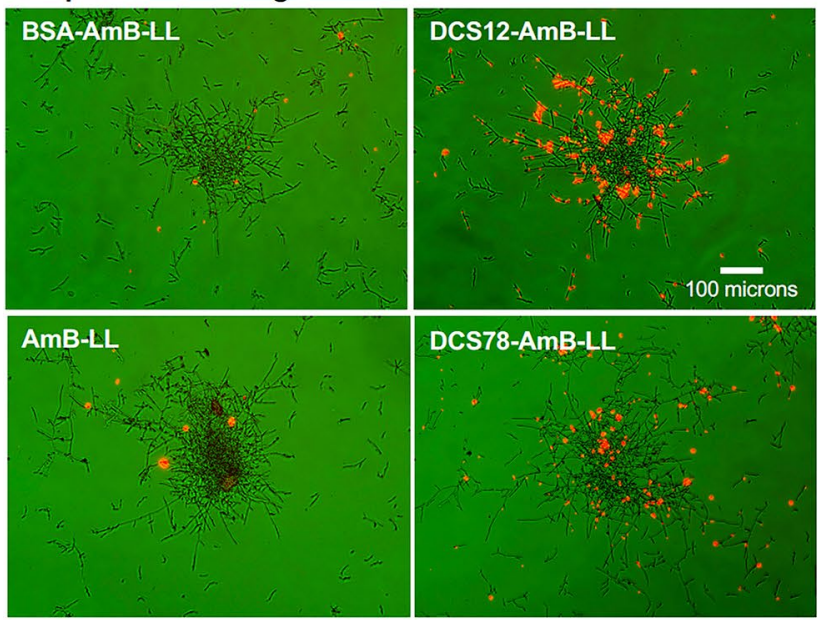

c. Liposome binding to A. fumigatus

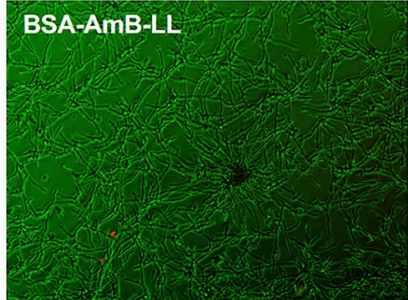

AmB-LL
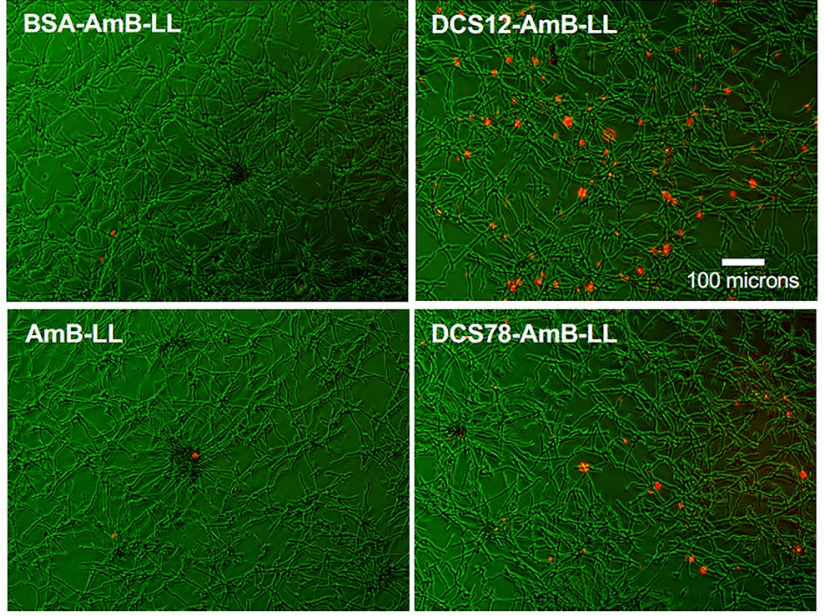

e. Liposome binding to $C$. neoformans

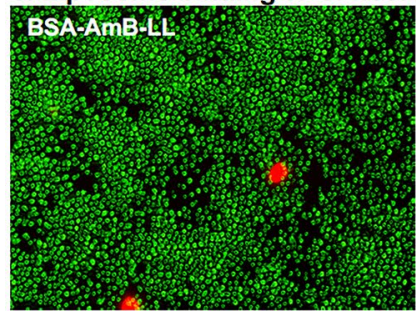

AmB:Lit:
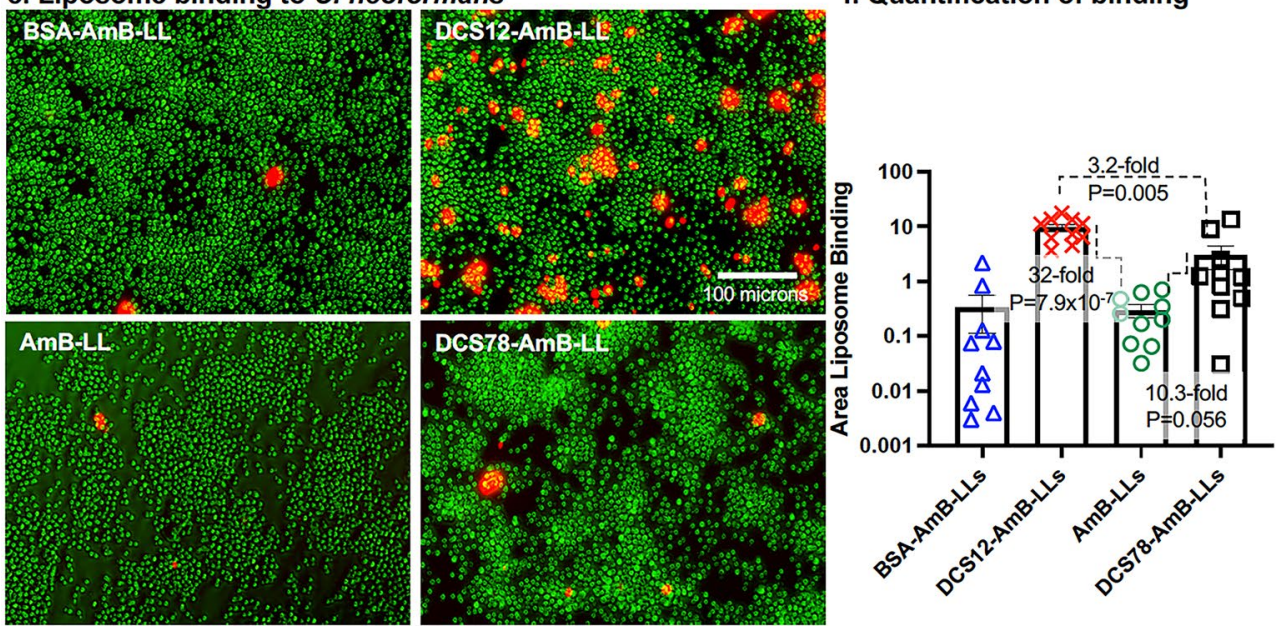

Fig. 2 DC-SIGN targeted liposomes, DCS12-AmB-LLs and DCS78-AmB-LLs, bound significantly more efficiently to the exopolysaccharide matrices of three highly divergent fungal pathogens than untargeted AmB-LLs. a, c, e Representative photographic images of fluorescent liposomes binding to bright field images of fungal cells are presented. a C. albicans ( $\times 10$ magnification). c A. fumigatus ( $\times 10$ magnification). e C. neoformans ( $\times 20$ magnification). $\mathbf{b}, \mathbf{d}, \mathbf{f}$ The relative area of red fluorescent liposome binding $\left(\log _{10}\right)$ was quantified as shown in scatter bar plots on the right. $N=10$ for each bar. $\mathbf{f}$ The scale of the plot for C. neoformans had to be expanded from three to five logs to accommodate more widely distributed data. Standard errors and $P$ values are indicted 


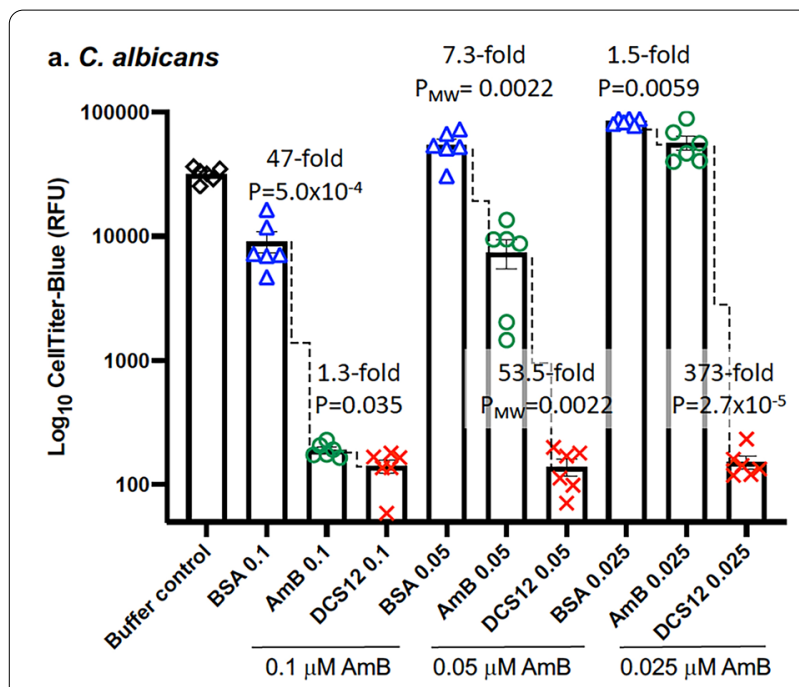

b. A. fumigatus

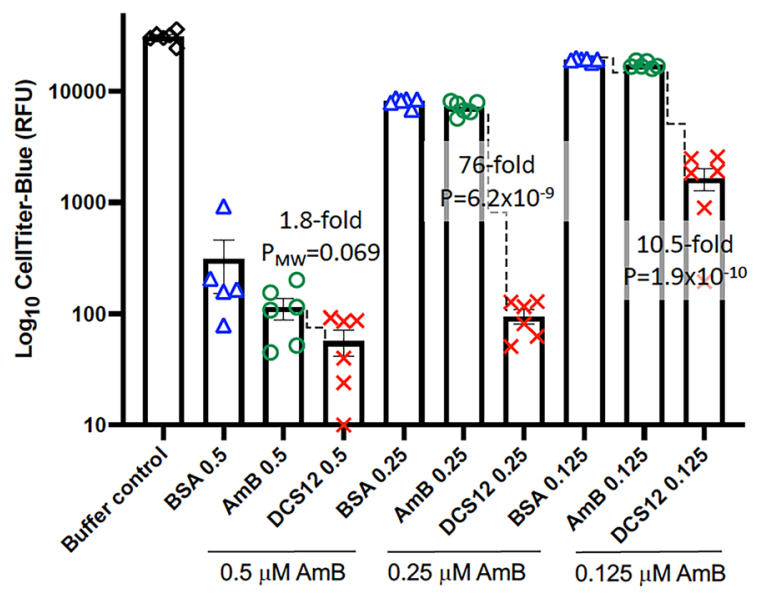

c. C. neoformans

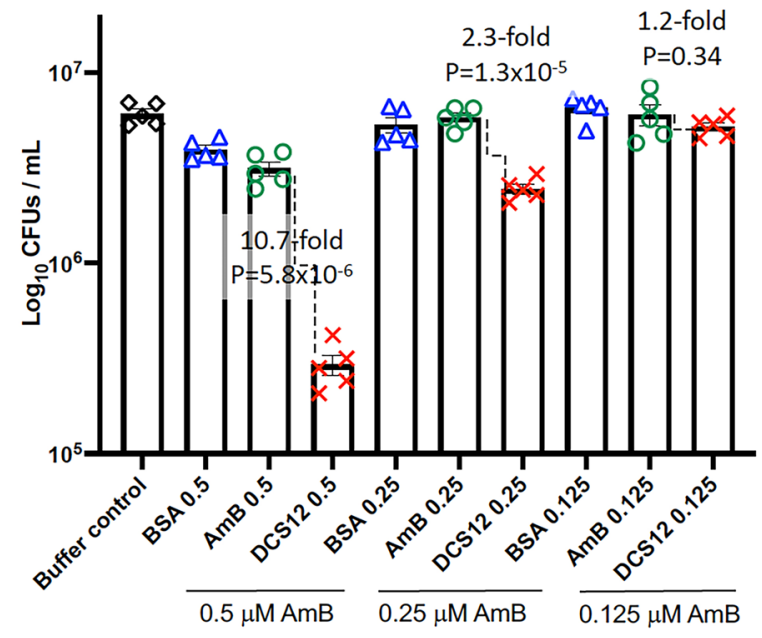

Fig. 3 DCS12-AmB-LLs more efficiently inhibited or killed three diverse fungal species in vitro than un-targeted control liposomes. In vitro grown fungal cells were treated with DCS12-AmB-LLs, BSA-AmB-LLs or AmB-LLs delivering the indicated concentrations of AmB or with liposome dilution buffer. a C. albicans hyphal cells growing in RPMl in microtiter plates were treated with liposomes delivering $0.1,0.05$ and $0.025 \mu \mathrm{M}$ AmB. Metabolic activity was measured as relative fluorescence units (RFU) generated from reduction of the CellTiter-Blue reagent. $\mathbf{b}$ A. fumigatus hyphal cells growing in RPMI in microtiter plates were treated with liposomes delivering $0.5,0.25$ and $0.125 \mu \mathrm{M}$ AmB. Metabolic activity was measured with CellTiter-Blue reagent. c C. neoformans yeast cells growing in liquid YPD suspension were treated in with liposomes delivering $0.5,0.25$ and $0.125 \mu \mathrm{M} \mathrm{AmB}$ and surviving cells assayed as CFUs. $\mathrm{N}=5$ or $\mathrm{N}=6$ for each bar. Scatter bar plots indicate the inhibition and/or killing of fungal cells. The fold-difference in RFUs or CFUs and $\mathrm{P}$ or $\mathrm{P}_{\mathrm{MW}}$ values are shown for informative comparisons

DCS12-AmB-LLs inhibited or killed three fungal species in vitro more efficiently than control liposomes

Candida albicans cells were grown in microtiter plates until they had reached the late germling and early hyphal stages. The cells were then treated for $1 \mathrm{~h}$ with AmB-LLs, BSAAmB-LLs or DCS12-AmB-LLs delivering AmB at the indicated concentrations. Metabolic activity was measured with CellTiter-Blue (CTB) reagent. CTB assays measure mitochondrial reductase activity that is linked to active electron transport in living cells, and which generates a fluorescent product. Compared to uncoated AmB-LLs delivering the same concentrations of AmB, targeted DCS12-AmB-LLs delivering 0.05 and $0.025 \mu \mathrm{M}$ AmB reduced the metabolic activity of $C$. albicans cells 53 -fold $(\mathrm{P}=0.0036)$ and 373 -fold $\left(\mathrm{P}=2.7 \times 10^{-5}\right)$ more efficiently, respectively (Fig. 3a). At a higher AmB concentration of $0.1 \mu \mathrm{M}, \mathrm{AmB}-\mathrm{LLs}$ were much more effective at inhibiting metabolic activity. Hence at this concentration, DCS12-AmB-LLs were only slightly more effective than AmB-LLs $(\mathrm{P}=0.035)$. Using even higher AmB concentrations of 0.2 or $0.4 \mu \mathrm{M}$ and more cells per well, we could not observe any differences between the performance of AmB-LLs and DCS12-AmB-LLs (Additional file 4: Fig. S3b). BSA-AmB-LLs were less effective than AmB-LLs, suggesting that coating liposomes with a protein that did not target them to fungal cells may have interfered with antifungal liposome activity. Biological replicates of this experiment confirmed that DCS12-AmB-LLs delivering low concentrations of $\mathrm{AmB}(0.05 \mu \mathrm{M}$ and $0.025 \mu \mathrm{M})$ performed significantly better than AmB-LLs (Additional file 4: Fig. S3a). The relatively low metabolic activity of cells in the Buffer treated control samples relative to some AmB-LL and BSA-AmBLL samples (Fig. 3a and Additional file 4: Fig. S3a) may have resulted from the cells having reached stationary phase and becoming metabolically less active or because the fluorescent product resorufin was further reduced to non-fluorescent hydroresorufin [31]. 
Aspergillus fumigatus conidia were germinated and grown to the early germling stage in microtiter plates and then treated for $4 \mathrm{~h}$ with liposomes delivering the indicated concentrations of AmB. The CTB assays of metabolic activity after treatment are shown in Fig. 3b. Compared to AmB-LLs, DCS12-AmB-LLs delivering 0.25 and $0.125 \mu \mathrm{M}$ $\mathrm{AmB}$ reduced the metabolic activity of $A$. fumigatus 76 -fold $\left(\mathrm{P}=6.2 \times 10^{-9}\right)$ and 10.5-fold $\left(\mathrm{P}=1.9 \times 10^{-10}\right)$ more efficiently, respectively. Because AmB-LLs were more inhibitory when delivering a higher $\mathrm{AmB}$ concentration of $0.5 \mu \mathrm{M}$, we could not detect a significant benefit from targeting at this concentration. Biological replicate experiments confirmed the superior performance of DCS12 targeted liposomes (Additional file 4: Fig. S3c).

Cryptococcus neoformans cells were grown in rich liquid medium, treated for $4 \mathrm{~h}$ with AmB-loaded liposomes, and grown overnight. The surviving cells were diluted onto agar plates and assayed as colony forming units per $\mathrm{mL}$ of media (CFUs/mL). DCS12-AmB-LLs delivering 0.5 and $0.25 \mu \mathrm{M} \mathrm{AmB}$ reduced the number of $C$. neoformans CFUs/mL 10.7-fold $\left(\mathrm{P}=5.8 \times 10^{-6}\right)$, 2.3-fold $\left(\mathrm{P}=1.3 \times 10^{-5}\right)$, respectively, relative to AmB-LLs delivering the same concentrations of AmB (Fig. 3c). A biological replicate is shown in Additional file 4: Fig. S3.

\section{DCS12-AmB-LL dramatically reduced the fungal burden in mouse models of invasive candidiasis and pulmonary aspergillosis}

In the candidiasis model, neutropenic mice were infected intravenously with $C$. albicans yeast cells and treated the same day with an intravenous injection of AmB-LLs or DCS12-AmB-LLs delivering $0.2 \mathrm{mg} / \mathrm{kg} \mathrm{AmB}$ or control buffer. At $24 \mathrm{~h}$ post infection (PI), the mice were euthanized and their fungal burden in the kidneys was measured. Mice treated with DCS12-AmB-LLs showed a 19-fold lower average number of CFUs per kidney pair relative to AmB-LL treated mice $\left(\mathrm{P}_{\mathrm{MW}}=0.002\right.$, Fig. $\left.4 \mathrm{a}\right)$ and 55-fold lower than buffer treated infected mice $\left(\mathrm{P}_{\mathrm{MW}}=0.002\right)$. Quantitative real time $\mathrm{qPCR}$ assays of the amount of fungal rDNA intergenic transcribe spacer (ITS) in duplicate samples revealed a 4.2-fold reduction in fungal burden in the DCS12-AmB-LLs group compared to AmB-LLs $\left(\mathrm{P}_{\mathrm{MW}}<0.0001\right.$, Fig. $\left.4 \mathrm{~b}\right)$ and a 24-fold reduction relative to buffer treated infected mice $\left(\mathrm{P}_{\mathrm{MW}}=0.0001\right)$. The differences between the results obtained from CFU and qPCR assays may be due to the contribution of DNA from dead cells in the DCS12AmB-LL sample assayed by qPCR. AmB-LLs produced a marginally significant 1.6 -fold and 1.8 -fold reductions in fungal burden relative to the buffer treated infected controls $(\mathrm{P}=0.087$ to 0.012$)$. Biological replicates of this experiment demonstrated the improved performance for DCS12-AmB-LLs over AmB-LLs (Additional file 5: Fig. S4a and $b)$.

In the aspergillosis model, neutropenic mice were infected by the oropharyngeal delivery of $A$. fumigatus conidia and the next day given an oropharyngeal treatment with liposomes delivering $0.2 \mathrm{mg} / \mathrm{kg} \mathrm{AmB}$ or control buffer. At 3 days PI, the mice were euthanized and their fungal burden in the lungs was measured. DCS12AmB-LLs treated mice showed a 13.6-fold lower average number of CFUs per lung relative to AmB-LL treated mice $\left(\mathrm{P}_{\mathrm{MW}}=0.002\right.$, Fig. $\left.4 \mathrm{c}\right)$ and 190 -fold reduction relative to buffer treated infected mice $\left(\mathrm{P}_{\mathrm{MW}}=0.002\right)$. $\mathrm{QPCR}$ assays of rDNA ITS in duplicate samples revealed a 3.2fold reduction in fungal burden in the DCS12-AmB-LLs relative to AmB-LLs treated mice $\left(\mathrm{P}_{\mathrm{MW}}<0.0004\right.$, Fig. $\left.4 \mathrm{~d}\right)$ and a 6.7-fold reduction relative to buffer treated mice $\left(\mathrm{P}_{\mathrm{MW}}=0.0001\right.$, Fig. $\left.4 \mathrm{~d}\right)$. At $0.2 \mathrm{mg} / \mathrm{kg}$, AmB-LLs significantly reduced the number of CFUs relative to buffer treated control mice $\left(\mathrm{P}_{\mathrm{MW}}=0.0087\right)$, but the difference was not statistically significant when assayed by qPCR $\left(\mathrm{P}_{\mathrm{MW}}=0.097\right)$. A biological replicate is shown in Additional file 5: Fig. S4c and d.

\section{Discussion}

We show that DC-SIGN is an effective liposome targeting protein. Alternate RNA splicing of DC-SIGN transcripts results in the expression of a variety of truncated membrane bound and soluble isoforms that combine the CRD with different numbers and combinations of neck repeats $[25,32]$. Our results both complement and expand the ligand specificity determined by others using various isoforms by showing that truncated isoforms DCS12 and DCS78 bound to three diverse fungal species and that DCS12 showed superior fungal binding over DCS78. We speculate that NR1 and NR2 orient the CRD in DCS12AmB-LLs in a more optimal conformation for binding fungal cognate ligands than provided by NR7 and NR8 in DCS78-AmB-LLs. The efficient binding of both isoforms to these three fungal pathogens gave us confidence that DCSIGN had potential as an anti-infective liposome targeting protein. Because DCS12 is a natural human isoform, it should have low immunogenicity if used in the clinic.

The minimum inhibitory concentrations $\left(\mathrm{MIC}_{50}\right)$ for commercial liposomal AmB (L-AmB, AmBisome ${ }^{\circledR}$ ) against Candida spp., Aspergillus spp., and Cryptococcus spp., which we will define as at least a $50 \%$ reduction in metabolic activity or in CFUs, varies modestly among previous publications and experimental designs. $\mathrm{MIC}_{50 \text { s }}$ are typically 4 to $8 \mu \mathrm{M}$ ( 3.7 to $7.4 \mathrm{mg} / \mathrm{L}$ ) for in vitro grown cells of all three species [33-35] and 5 to $20 \mathrm{mg} /$ $\mathrm{kg}$ to suppress fungal burden and significantly improve 
mouse survival in immune-suppressed mouse models of candidiasis and aspergillosis [34, 36, 37]. We showed that order of magnitude lower concentrations of AmB delivered as DCS12-AmB-LLs significantly reduced cell viability in vitro, concentrations at which AmB-LLs were relatively ineffective. The presence of metabolically inactive cells that resist high drug concentrations in biofilms (e.g., persister cells) may necessitate extended treatments in vivo [38]. Yet, we showed that single low doses of $A m B$ delivered as DCS12-AmB-LL dramatically reduced fungal cell numbers in kidney and lungs and were significantly more effective than untargeted AmB-LLs at these concentrations. Lower effective doses of $\mathrm{AmB}$ should translate into greater efficacy and reduced antifungal drug toxicity in the clinic. In the future we will need to specifically examine the potential of DC-SIGN targeted antifungal liposomes against biofilms.

The present study of DC-SIGN-targeted antifungal liposomes is a continuation of our efforts to design DectiSomes for pan-antifungal therapies with increased efficacy [1-5]. We have previously shown that Dectin-1 and Dectin-2 are effective at targeting liposomes to fungal cells (1-5). Herein we showed that DC-SIGN targeting improved the performance of liposomal AmB against three highly divergent fungal species, whose common ancestry dates nearly to the divergence of the fungal kingdom from its animal and protist ancestries [21]. Goyal et al. [6] summarized what is known about 13 C-type lectin pathogen receptors that recognized one or more representative species from 20 distinct genera of fungal pathogens. In addition to the three genera of fungal pathogens represented herein, they reported that DC-SIGN also recognizes Talaromyces spp. (f.k.a., Penicillium spp.), Saccharomyces spp., and Chrysosporium spp., 6 of the 20 genera of pathogenic fungi [6]. Considering the evolutionary depth of fungal recognition by DC-SIGN, it is reasonable to propose that DC-SIGN coated liposomes might effectively deliver anti-infective drugs to life-threatening pathogens from other kingdoms, whose oligoglycans and lipoglycans are also recognized by DC-SIGN. For example, DC-SIGN binds cognate ligands expressed by the bacterium Mycobacterium tuberculosis [15], the animal helminth Schistosoma mansoni [39], and the protist Leishmania infantum [40] and hence may be effective at targeting lipid nanoparticle packaged anti-infectives to pathogens from these kingdoms. Respectively, these pathogens cause millions, hundreds of thousands, and tens of thousands of deaths annually and drug treatment failures are common for all three [41, 42]. It is worth noting that AmBisome ${ }^{\circledR}$ has been an FDA approved treatment for visceral leishmaniasis since 1997 [43].

In this study we had remotely intercalated the hydrophobic end of amphiphobic AmB into the bilipid membrane of preformed liposomes (Fig. 1). We have previously remotely incorporated the amphiphobic echinocandin antifungal, anidulafungin, into liposomes [2]. There are a variety of methods for remote loading of both hydrophilic and hydrophobic drugs into liposomes [44]. Remote loading methods have allowed us to work on smaller scale than older organo-chemical methods, which for example, may involve flash evaporators. However, newer microfluidic methods are scalable and microfluidics simplifies and speeds up the assembly of various types of lipid nanoparticles from constituent lipids and almost any class of drug beyond remote loading methods $[45,46]$. Indeed Pfizer's and Moderna's Spike mRNA lipid nanoparticle vaccines are both produced using microfluidic methods [47]. In the future we plan to construct DectiSomes using microfluidics.

The AmB-LLs employed herein are pegylated liposomes in which $5 \%$ of their constituent lipids are the pegylated lipid mPEG2000-DSPE (Additional file 1: Table S1), wherein the partially negatively charged hydroxyl rich PEG group is proposed to be on the outside of the liposomes in the aqueous environment (Fig. 1). The first amphotericin B loaded lipid nanoparticle drugs, including AmBisome ${ }^{\circledR}$, were approved for clinical use in the midto late 1990s and were not pegylated [48], likely because the benefits of pegylated nanoparticles $[49,50]$ were not yet fully appreciated. Pegylated liposomes are protected from opsonization and phagocytosis [51] and for this reason are called stealth liposomes [52]. The half-lives of packaged drugs are extended in pegylated liposomes. We recently demonstrated that our pegylated AmB-LLs significantly outperform AmBisome ${ }^{\circledR}$ in a mouse model of disseminated candidiasis [2], presumably because pegylation extends the effective half-life of the liposomal AmB. In addition, we also have shown that the Dectin targeting

\footnotetext{
(See figure on next page.)

Fig. 4 DCS12-AmB-LLs were significantly more effective at reducing the number of C. albicans cells in the kidneys and A. fumigatus in the lungs than AmB-LLs in mouse models of disease. Neutropenic mice with invasive candidiasis and pulmonary aspergillosis were treated with DCS12-AmB-LLs or AmB-LLs delivering $0.2 \mathrm{mg} / \mathrm{kg}$ AmB or with liposome dilution buffer. $\mathbf{a}, \mathbf{b}$ Fungal burden of C. albicans in the kidneys. $\mathbf{c}, \mathbf{d}$ Fungal burden of A. fumigatus in the lungs. $\mathbf{a}$, $\mathbf{A}$ A scatter bar plot compares the average number of CFUs per mouse kidneys or lungs for the three treatment groups. Each mouse is represented by one data point. b, d The Relative Quantity (RQ) of fungal rDNA intergenic spacer (IGS) was determined by qPCR using species specific primers on parallel samples of kidney and lung homogenates from the same mice used to assay CFUs. Three replicates qPCR reactions were run on each sample. $N=6$ mice for each treatment group. Standard errors are indicated. Fold differences and T.Test determined $P$ values or Mann-Whitney determined $P_{M w}$ values are shown for informative comparisons
} 


\section{C. albicans in the kidneys}

a. Colony Forming Units

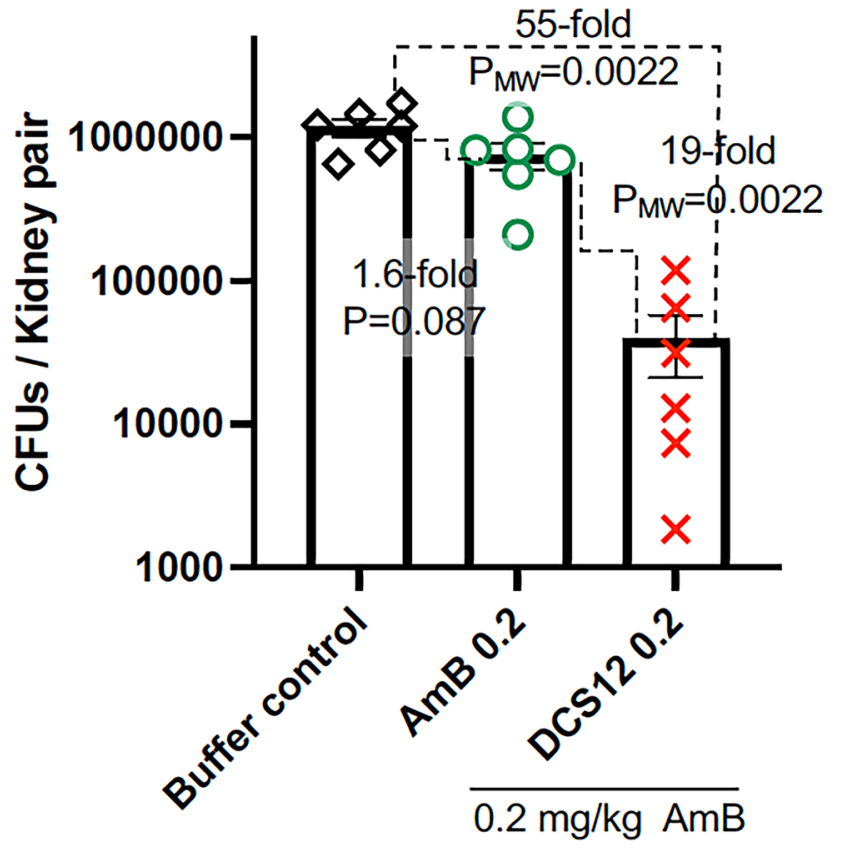

b. Quantitative Real-time PCR

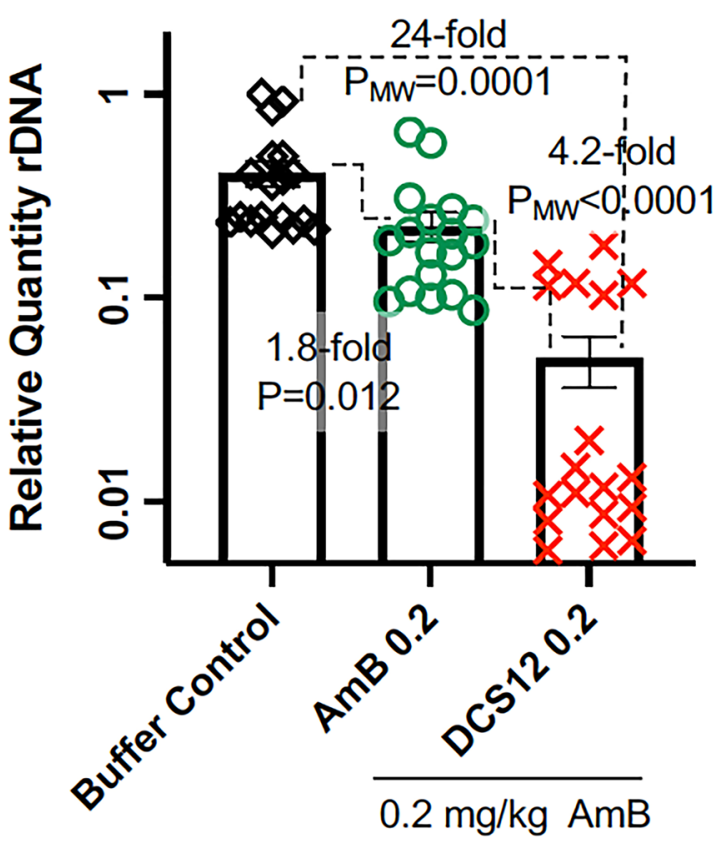

A. fumigatus in the lungs

c. Colony Forming Units

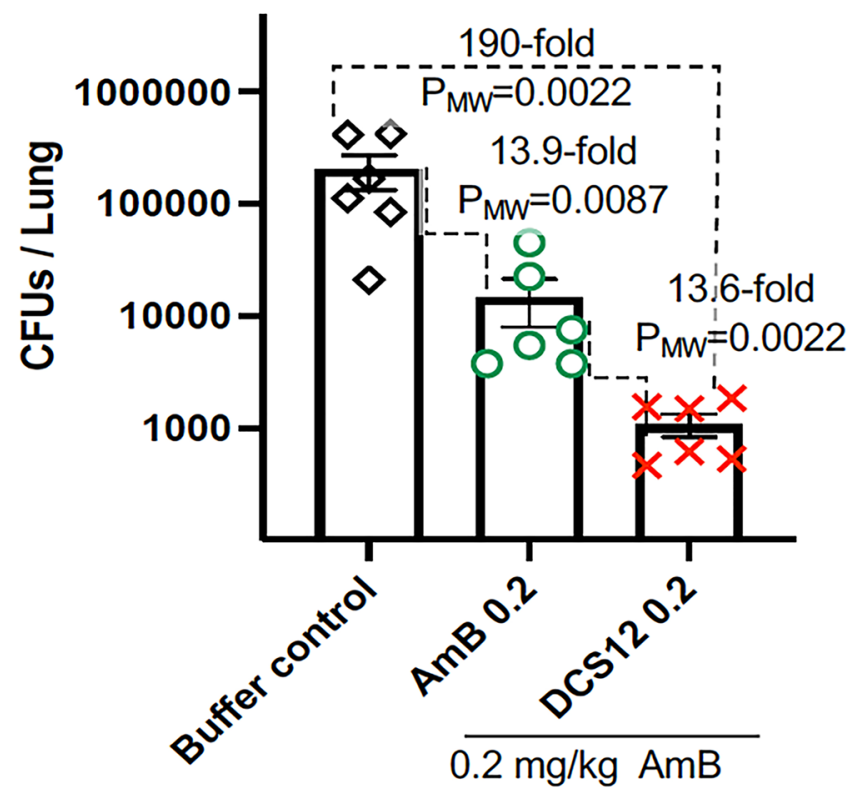

d. Quantitative Real-time PCR

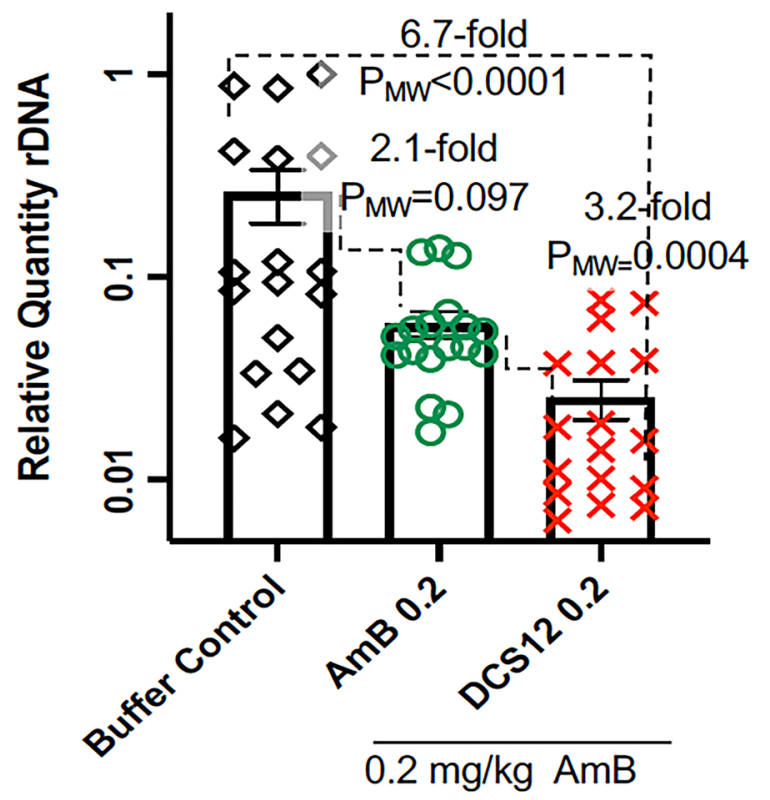


of AmBisome ${ }^{\circledR}$ improves its performance in the mouse candidiasis model [2], generalizing the benefits of targeting to other lipid nanoparticle preparations.

\section{Conclusions}

DCS12 is a truncated recombinant isoform of DC-SIGN constructed from part of a natural full-length DC-SIGN isoform, while DCS78 is part of a truncated recombinant isoform with no known homolog in nature. Compared to untargeted liposomes, DCS12-AmB-LLs and DCS78-AmB-LLs bound at significantly higher levels to the exopolysaccharide matrices associated with $C$. albicans, A. fumigatus, and C. neoformans grown in vitro, with DCS12-AmB-LLs showing superior binding activity. DCS12-AmB-LLs were far more effective at inhibiting and/or killing all three fungal species in vitro than AmBLLs or BSA-AmB-LLs. In neutropenic mouse models of invasive candidiasis and pulmonary aspergillosis, DCS12AmB-LLs were significantly more effective in reducing fungal burden in the kidneys and lungs than untargeted AmB-LLs. By dramatically lowering the effective dose of antifungal drug, DCS12-AmB-LLs have the potential to overcome dose dependent drug resistance and perhaps persister-like cells in biofilms. DC-SIGN is the third C-type lectin we've used to construct DectiSomes that had improved liposomal drug performance. Collectively, these results begin to generalize the benefits of targeting anti-infective liposomes to diverse pathogenic cells using pathogen receptor CRDs. DC-SIGN-targeted antiinfective drug-loaded liposomes may also be effective at treating pathogens in the bacterial, animal, and protist kingdoms that express DC-SIGN's cognate ligands.

\section{Methods}

\section{Aim, design, and study setting}

The aim of this study was to show that DectiSomes coated with the CRD and two NRs of DC-SIGN targeted anti-infective loaded liposomes to diverse fungal species. Based on the structures modeled for DC-SIGN monomers and multimers, we predicted that two NRs might optimally position the CRD for glycan binding by liposomes as illustrated in Fig. 1d [23]. Drug loaded liposomes were coated with recombinant isoforms of DC-SIGN and used to treat fungal cells. Quantitative binding assays, metabolic and growth assays in vitro, and fungal burden assays in vivo in mouse models of fungal diseases were employed to examine efficacy.

\section{Strains of fungi and medium}

Three fungal species were examined herein and grown on polystyrene 24- (Costar) or 96-well (BD Falcon) microtiter plates without agitation or grown in liquid suspension with agitation. C. albicans strain CA14 [53] derived from a human isolate (SC5314, ATCC MYA-2876) that was subsequently deleted for URA3 (strain CA14, Dura3::imm434/Dura3::434) [54] and A. fumigatus A1163 were grown in RPMI 1640 medium with no phenol red pH indicator (Sigma \#R8755) + 0.5\% BSA (Sigma \#A7906) or $+10 \%$ fetal bovine serum (Life Technologies GIBCO \#16170-078) at $37^{\circ} \mathrm{C}$. The preparation of $A$. fumigatus conidia was described previously [4]. C. neoformans clinical isolate H99 [55] was grown in YPD (1\% yeast extract, $2 \%$ peptone, $2 \%$ dextrose) with $0.5 \% \mathrm{BSA}$ at $32{ }^{\circ} \mathrm{C}$. $\mathrm{H} 99$ grows better in vitro at $32{ }^{\circ} \mathrm{C}$ than at $37^{\circ} \mathrm{C}$.

\section{Mice}

Seven- to eight-week-old outbred female CD1 (CD-1 IGS) Swiss mice (27 g to $30 \mathrm{~g}$ ea.) were obtained from Charles River Labs. Six mice were housed per cage, given $12 \mathrm{~h}$ light and $12 \mathrm{~h}$ dark per day, maintained on a standard $20 \%$ protein diet (PicoLab ${ }^{\circledR}$ Rodent diet 20, LabDiet \#5053), and given water liberally. Mice were rendered neutropenic by treating them 3 days prior to infection with $150 \mathrm{mg} / \mathrm{kg}$ of the antimetabolite cyclophosphamide and $75 \mathrm{mg} / \mathrm{kg}$ of the corticosteroid triamcinolone [5]. Mice were maintained in UGA's Animal Care Facility.

\section{Preparation of DC-SIGN isoforms and integrating them into AmB loaded liposomes}

The carboxyterminal extracellular CRD of DC-SIGN is hydrophobic and thus relatively insoluble in normal biological buffers. Soluble functional isoforms are inefficiently recovered from E. coli. For example, it was reported that only 0.5 to $0.7 \mathrm{mg}$ of soluble DCSIGN was recovered from a liter of isopropyl $\beta$-D-1thiogalactopyranoside (IPTG) induced E. coli cultures in one of the best previous studies [24]. DCS12 and DCS78 polypeptides are predicted to be unstable and insoluble hydrophobic proteins (https://web.expasy. org/protparam/). Here we applied the same technologies that we used to overcome such difficulties in manipulating Dectin-1 and Dectin-2 $[3,4]$ to obtain modest quantities of DCS12 and DCS78 as summarized briefly here. E. coli optimized DNA encoding sequences were cloned into expression plasmid pET-45b + and transformed into E. coli strain BL21. Following $4 \mathrm{~h}$ induction with IPTG, the protein was solubilized and extracted from cell pellets in a $6 \mathrm{M}$ Guanidine hydrochloride $(\mathrm{GuHCl})$ buffer and affinity purified on nickel affinity resin. Approximately $40 \mathrm{mg}$ of 75 to $80 \%$ pure DCS12 and DCS78 peptides were recovered (Additional file 3: Fig. S2). While still in a $6 \mathrm{M} \mathrm{GuHCl}$ buffer, DCS12 and DCS78 were coupled with the lipid carrier DSPE-PEG-3400-NHS. Gel exclusion chromatography over Bio-Gel P6 acrylamide resin was used to remove $\mathrm{GuHCl}$ and excess hydrolyzed 
coupling agent and to buffer exchange the protein into a $1 \mathrm{M}$ arginine crowding buffer with beta-mercaptoethanol (BME) [4]. BSA was coupled via a native lysine amino group to DSPE-PEG-3400-NHS.

AmB-LLs were prepared as described previously by the remote loading of $\mathrm{AmB}$ into $100 \mathrm{~nm}$ diameter FormuMax liposomes (F10203, Plain) [4]. AmB-LLs are pegylated analogs of commercial unpegylated $\mathrm{AmBi}$ some $^{\circledR}$ (a.k.a. L-AmB), with an equivalent amount of $\mathrm{AmB}, 11$ moles percent relative to moles of liposomal membrane lipids, but a different lipid profile (Additional file 1: Table S1). The modified DCS12PEG-DSPE and DCS78-PEG-DSPE proteins remained soluble in the $1 \mathrm{M}$ arginine buffer and were integrated via their DSPE lipid moieties into the phospholipid bilayer membrane of AmB-LL at 1.0 mol percent relative to moles of liposomal lipid to make DCS12-AmBLLs and DCS78-AmB-LLs (Additional file 1: Table S1). As a protein coated control, we made liposomes coated with 0.33 moles percent bovine serum albumin, BSAAmB-LLs. We reduced the molar amount of BSA $(65 \mathrm{kDa})$, because it is about three times larger than DCS12 $(24.9 \mathrm{kDa})$ or DCS78 $(24.2 \mathrm{kDa})$, and thus BSAAmB-LLs are coated with an equivalent $\mu g$ amount of protein (Additional file 1: Table S1). Lissamine rhodamine B-DHPE was simultaneously incorporated at two moles percent in all liposome preparations (Fig. 1d), allowing sensitive and quantitative comparisons of fluorescence to estimate the binding efficiency of all four liposomal preparations to fungal cells. DCS12-AmBLL and DCS78-AmB-LL stocks were stored in the $1 \mathrm{M}$ arginine buffer [4] such that the AmB concentration ranged from 600 to $800 \mu \mathrm{M}$. Fresh BME was added to $0.1 \mathrm{mM}$ every month during storage. Liposomes remained active in their binding activity for several months when stored at $4{ }^{\circ} \mathrm{C}$. Just prior to their use, DCS12 and DCS78 liposomal stocks were diluted with LDB2 buffer (20 mM HEPES, $10 \mathrm{mM}$ triethanolamine, $150 \mathrm{mM} \mathrm{NaCl}, 10 \mathrm{mM} \mathrm{CaCl}_{2}$, fresh $1 \mathrm{mM}$ beta-mercaptoethanol (BME), $\mathrm{pH}$ 8.0) or with growth medium. None of the liposome preparations examined herein aggregate significantly upon dilution into liposome dilution buffer or into growth medium.

\section{Microscopy and quantification of liposome binding to fungal cells}

Cells to be photographed were grown in 24-well microtiter plates, washed thrice with phosphate buffered saline (PBS), fixed in $4 \%$ formaldehyde in PBS for $60 \mathrm{~min}$, washed thrice, and stored at $4{ }^{\circ} \mathrm{C}$ in PBS. Fixed fungal cells were pre-incubated for 30 to $60 \mathrm{~min}$ with in LDB2 $+5 \%$ BSA at $23{ }^{\circ} \mathrm{C}$. Liposomal stocks were freshly diluted approximately 100 -fold into LDB2 $+5 \%$ BSA on the same day they were to be used and then incubating with cells such that the DCS12 or DCS78 or BSA protein concentration was approximately $1.0 \mu \mathrm{g} / 100 \mu \mathrm{L}$. After $1 \mathrm{~h}$ incubation at $23^{\circ} \mathrm{C}$, unbound liposomes were washed out with 4 changes of LDB2 $+5 \%$ BSA. Ten separate fluorescent images of rhodamine red fluorescent liposomes bound to cells grown on 24 well microtiter plates were taken at $10 \times$ or $20 \times$ magnification on an Olympus inverted microscope (Model IX70) with a digital camera. The relative area of red fluorescent liposome binding from 10 random images was quantified by taking an 8-bit grey-scale copies of the unmodified red fluorescent JPEG images into Image J (imagej.nih.gov/ij) as described previously for Dectin-2 coated liposomes [3]. The green channel of bright field images showing fungal cells and the red fluorescent images of liposomes were merged in Photoshop and enhanced for image presentation.

\section{Growth inhibition and viability assays following liposome treatment}

Cell viability and metabolic activity after AmB loaded liposome treatment was assayed by a protocol modified from that described previously [3]. C. albicans yeast cells grown in YPD were inoculated at 4000 cells per well in 96 well microtiter plates in RPMI and grown for $7 \mathrm{~h}$ at $37^{\circ} \mathrm{C}$. Liposomal stocks were freshly diluted 1000 -fold or more into fresh LDB2 buffer $+0.5 \% \mathrm{BSA}$ and then 1:11 into growth medium to achieve the indicated final AmB concentrations. Control cells received an equivalent amount of buffer. After $1 \mathrm{~h}$ incubation at $37{ }^{\circ} \mathrm{C}$, the plates were gently agitated for a few seconds and unbound liposomes were removed without further washing. $100 \mu \mathrm{L}$ of fresh RPMI growth medium was added. After $4.5 \mathrm{~h}$ incubation at $37^{\circ} \mathrm{C}, 20 \mu \mathrm{L}$ of blue non-fluorescent CTB reagent resazurin (Promega Corp.) was added per well as per the manufacturer's instructions. After $1.5 \mathrm{~h}$ incubation at $37{ }^{\circ} \mathrm{C}$ the fluorescent product resorufin was analyzed in a Bio-Tek Synergy HT fluorescent microtiter plate reader (ex485/em590). The fluorescent background from control wells with reagent, but no cells, was subtracted from readings of experimental wells. Data from six wells were averaged for each data point. CTB assays on A. fumigatus cells were performed using the same protocol in RPMI medium, except that 5000 conidia per well were grown for $8 \mathrm{~h}$ until they reached early germling stage, treated with liposomes for $4 \mathrm{~h}$, washed once, grown overnight in fresh medium, and then examined for reductase activity.

In our hands CTB assays do not work for C. neoformans [3]. Therefore, we assayed growth inhibition and killing as percentage of surviving colony forming units (CFUs) after treatment in liquid medium. A fresh overnight culture of $C$. neoformans cells grown in YPD was diluted to 5000 cells $/ \mathrm{mL}$, grown for $3 \mathrm{~h}$ with shaking at 
$200 \mathrm{rpm}$, treated with liposomes delivering the indicated concentrations of $\mathrm{AmB}$ for $4 \mathrm{~h}$ with shaking, washed once, and grown in fresh medium overnight. The cells were diluted, plated on YPD agar, and the number of CFUs/mL of culture medium recorded.

\section{Fungal burden measurement}

Neutropenic mice were infected intravenously with $7.5 \times 10^{6} \mathrm{C}$. albicans yeast cells in $100 \mu \mathrm{L}$ of PBS or by the oropharyngeal delivery of $1.0 \times 10^{6} \mathrm{~A}$. fumigatus conidia in $50 \mu \mathrm{L}$ on Day zero. In the candidiasis model, mice were given an intravenous treatment $3 \mathrm{~h}$ PI with AmB-loaded liposomes. Fungal burden at $24 \mathrm{~h}$ PI in excised homogenized kidney pairs was estimated. In the pulmonary aspergillosis model, mice were given an oropharyngeal liposomal drug treatment at $20 \mathrm{~h}$ PI. Fungal burden in excised and homogenized lungs was estimated at day 3 PI. Organs were weighed and minced into hundreds of approximately $1 \mathrm{~mm}^{3}$ pieces, the pieces mixed to account for the uneven distribution of infection sites, and aliquoted into $25 \mathrm{mg}$ samples. For CFUs assay, $25 \mathrm{mg}$ of the minced kidney or lung tissue was homogenized for $60 \mathrm{~s}$ in $200 \mu \mathrm{L}$ of PBS using a hand-held battery powered homogenizer (Kimble, cat\#749540-0000) and blue plastic pestle (Kimble Cat\#749521-1500). The homogenates were spread on YPD agar plates containing $100 \mu \mathrm{g} / \mathrm{mL}$ each of Kanamycin and Ampicillin, and CFUs were counted $[2,5]$. For qPCR assays, DNA was extracted from parallel $25 \mathrm{mg}$ samples of kidney and lung homogenates using Qiagen's DNeasy ${ }^{\circledR}$ Blood \& Tissue Kit (\#69504) protocol modified with a bead beater step as we described previously [5]. qPCR was used to estimate the relative quantity of $r D N A$ ITS in $100 \mathrm{ng}$ samples of infected organ DNA using the conditions and speciesspecific primers described previously $[2,5]$.

\section{Data management}

Data were recorded and managed in Excel (v. 16.16.27). Scatter bar plots were prepared and standard errors estimated in Graph Pad Prism 9 (v. 9.0.0). Most of the data were normally distributed, so the student's two-tailed $t$ test, T.TEST in Excel, was used to estimate P values. In those cases where the data for at least one sample in a comparison appeared to be non-parametric in their distribution, $P$ values were estimated using the Mann-Whitney test in Prism 9 and were indicated as $\mathrm{P}_{\mathrm{MW}}$ values.

\footnotetext{
Abbreviations

DC-SIGN: Dendritic Cell-Specific ICAM-3-Grabbing Non-Integrin 1, DC-SIGN1, CD-SIGN, CD209); AmB: Amphotericin B; CRD: Carbohydrate recognition domain; qPCR: Quantitative real time PCR; CFU: Colony forming units; GuHCl: Guanidine hydrochloride.
}

\section{Supplementary Information}

The online version contains supplementary material available at https://doi. org/10.1186/s40694-021-00126-3.

Additional file 1: Table S1. Liposome composition compared to that of Gilead's AmBisome. https://www.astellas.us/docs/ambisome

Additional file 2: Fig. S1. Amino acid sequences of human DC-SIGN, DCS12 and DCS78. a Annotated amino acid (a.a.) sequence of full-length human DC-SIGN (CD209 Q9NNX6.1, 404 a.a.). b Annotated a.a. sequence of recombinant isoform DCS78. c. Annotated a.a. sequence of recombinant isoform DCS12

Additional file 3: Fig S2. SDS PAGE analysis of affinity purified DCS12 and DCS78 polypeptides, before and after coupling to DSPE-PEG-NHS. Samples were resolved on a $12 \%$ polyacrylamide gel and stained with Coomassie Blue. Color coded molecular weight markers visible before Coomassie staining were tagged by poking carbon particles into the gel with a needle. Their sizes are indicated in kilo-Daltons ( $k D a)$. PEG is extremely hydrophilic, alters protein migration, and reduces the efficiency of Coomassie protein staining of hydrophobic protein domains.

Additional file 4: Fig. S3. Replicates of experiments in Fig. 3 showing the inhibition or killing of three fungal species by DCS12-AmB-LLs and AmB-LLs delivering various AmB concentrations in vitro. a A biological replicate of Fig. 3a. Wells of a microtiter plate were inoculated with 4000 C. albicans yeast cells per well. Cells were grown to late germling and early hyphal stages and treated for $60 \mathrm{~min}$ with liposomes delivering 0.1, 0.05 and $0.025 \mu \mathrm{M}$ AmB. For experimental details see legend to Fig. 3 and Material and Methods. b This experiment was conducted and analyzed by methods similar to those described in Fig. 3a and Additional file 4: Fig. S3a except that plates were inoculated with 40,000 cells per microtiter well instead of 4000 cells/well, higher concentrations of AmB were explored, and cells were only grown for $3 \mathrm{~h}$ after liposomes were removed and just before adding CTB reagent. c Inhibition and killing of $A$. fumigatus grown in microtiter plates seeded with 4,500 conidia per well. d. Inhibition and killing of $C$. neoformans grow in liquid. Standard errors are indicated with a bar and whisker. $\mathrm{N}=5$ or $\mathrm{N}=6$ for each bar. Fold differences and $\mathrm{P}$ or $P_{\text {MW }}$ values for comparisons between DCS12-AmB- $L L$ and AmB- $L L$ treated fungi are indicated.

Additional file 5: Fig. S4. Replicate experiments showing DCS12-AmBLLs were significantly more effective at reducing the number or viability of C. albicans in the kidneys and A. fumigatus in the lungs than AmB-LLs in two distinct mouse models of disease (see Fig. 4). Neutropenic mice with invasive candidiasis and pulmonary aspergillosis were treated with DCS12AmB-LLs or AmB-LLs delivering $0.2 \mathrm{mg} / \mathrm{kg} \mathrm{AmB}$ or with liposome dilution buffer. a, b Fungal burden of C. albicans in the kidneys. c, d Fungal burden of $A$. fumigatus in the lungs. a, c Scatter bar plots compares the average number of CFUs per kidney pair or lung pair for the three treatment groups. Each mouse is represented by one data point. b, d The Relative Quantity (RQ) of fungal rDNA intergenic spacer (IGS) was determined by qPCR using species specific primers on parallel samples of kidney and lung homogenates from the same mice used to assay CFUs. Three replicates $q P C R$ reactions were run on each sample. $N=6$ mice for each treatment group. Standard errors are indicated. Fold differences and T.Test determined $P$ values or Mann-Whitney determined $P_{M W}$ values are shown.

\section{Acknowledgements}

The authors wish to thank Kristine Wilcox and the other staff members of UGA's University Research Animal Facilities for the conscientious care of mice.

\section{Authors' contributions}

$\mathrm{RBM}, \mathrm{ZAL}$ and $\mathrm{XL}$ conceived of the project and obtained the funding. SA led the execution of wet-bench experiments and collection of data with assistance from TP and RBM. RBM drafted the manuscript and prepared the figures. The manuscript was edited by all the authors. All authors read and approved the final manuscript. 


\section{Funding}

R.B.M., S.A., and Z.A.L. received funding from the National Institutes of Health, NIAID (Grants R21Al144498 and R21Al148890), the Georgia Research Alliance, and the University of Georgia Research Foundation (UGARF). T.P. and X.L. received funding from NIAID (R21AI150641) and UGARF. These funding agencies are not responsible for the content of this article.

\section{Availability of data and materials}

All new data discussed are presented within this publication and any data obtained from other publications were appropriately cited.

\section{Declarations}

\section{Ethics approval and consent to participate}

All mouse protocols met guidelines for the ethical treatment of non-human animals outlined by the U.S. Federal government and were approved by UGA's Institutional Animal Care and Use Committee as described in our animal use protocols, AUPs A2019 08-031-A1 and A2018 12-009-Y2-A2.

\section{Consent for publication}

Consent for publication is not required by the University of Georgia.

\section{Competing interests}

A provisional patent was submitted to the United States Patent and Trademark Office.

\section{Author details}

${ }^{1}$ Department of Genetics, University of Georgia, Athens, GA 30602, USA.

${ }^{2}$ Department of Microbiology, University of Georgia, Athens, GA 30602, USA.

Received: 16 September 2021 Accepted: 17 November 2021

Published online: 24 December 2021

\section{References}

1. Meagher R, Lewis Z, Ambati S, Lin X. Aiming for a bull's-eye: targeting antifungals to fungi with dectin-decorated liposomes. PLoS Pathog. 2021;17(7):1-7.

2. Ambati S, Pham T, Lewis ZA, Lin X, Meagher RB. DectiSomes-glycan targeting of liposomal amphotericin $b$ improves the treatment of disseminated Candidiasis. Antimicrob Agents Chemother. 2021. https://doi. org/10.1128/AAC.01467-21.

3. Ambati S, Ellis EC, Lin J, Lin X, Lewis ZA, Meagher RB. Dectin-2-targeted antifungal liposomes exhibit enhanced efficacy. mSphere. 2019;4(5):1-16.

4. Ambati S, Ferarro AR, Kang SE, Lin J, Lin X, Momany M, et al. Dectin1-targeted antifungal liposomes exhibit enhanced efficacy. mSphere. 2019;4(1):1-15.

5. Ambati S, Ellis EC, Pham T, Lewis ZA, Lin X, Meagher RB. Antifungal liposomes directed by dectin-2 offer a promising therapeutic option for pulmonary aspergillosis. mBio. 2021;12(1):1-8.

6. Goyal S, Castrillon-Betancur JC, Klaile E, Slevogt H. The interaction of human pathogenic fungi with C-type lectin receptors. Front Immunol. 2018;9:1261-85

7. Vazquez-Mendoza A, Carrero JC, Rodriquez-Sosa M. Parasitic infections: a role for C-type lectins receptors. BioMed Res Int. 2013;2013:456352.

8. Holla A, Skerra A. Comparative analysis reveals selective recognition of glycans by the dendritic cell receptors DC-SIGN and Langerin. Protein Eng Des Sel. 2011;24(9):659-69. https://doi.org/10.1093/protein/gzr016.

9. Sawettanai N, Leelayuwapan H, Karoonuthaisiri N, Ruchirawat S, Boonyarattanakalin S. Synthetic lipomannan glycan microarray reveals the importance of alpha(1,2) mannose branching in DC-SIGN binding. J Org Chem. 2019;84(12):7606-17.

10. Reina JJ, Diaz I, Nieto PM, Campillo NE, Paez JA, Tabarani G, et al. Docking, synthesis, and NMR studies of mannosyl trisaccharide ligands for DCSIGN lectin. Org Biomol Chem. 2008;6(15):2743-54

11. Feinberg H, Castelli R, Drickamer K, Seeberger PH, Weis WI. Multiple modes of binding enhance the affinity of DC-SIGN for high mannose $\mathrm{N}$-linked glycans found on viral glycoproteins. J Biol Chem. 2007:282(6):4202-9.
12. Amraei R, Yin W, Napoleon MA, Suder EL, Berrigan J, Zhao Q, et al. CD209L/L-SIGN and CD209/DC-SIGN act as receptors for SARS-CoV-2. ACS Cent Sci. 2021:7(7):1156-65.

13. White RR, Artavanis-Tsakonas K. How helminths use excretory secretory fractions to modulate dendritic cells. Virulence. 2012;3(7):668-77.

14. Njiri OA, Zhang X, Zhang Y, Wu B, Jiang L, Li Q, et al. CD209 C-type lectins promote host invasion, dissemination, and infection of Toxoplasma gondii. Front Immunol. 2020;11:656. https://doi.org/10.3389/fimmu.2020. 00656.

15. Tailleux L, Schwartz O, Herrmann J-L, Pivert E, Jackson M, Amara A, et al. DC-SIGN is the major Mycobacterium tuberculosis receptor on human dendritic cells. J Exp Med. 2003;197(1):121-7.

16. Geijtenbeek TB, den Dunnen J, Gringhuis SI. Pathogen recognition by DC-SIGN shapes adaptive immunity. Future Microbiol. 2009;4(7):879-90.

17. den Dunnen J, Gringhuis SI, Geijtenbeek TB. Innate signaling by the C-type lectin DC-SIGN dictates immune responses. Cancer Immunol Immunother. 2009;58(7):1149-57.

18. Garcia-Vallejo JJ, van Kooyk Y. The physiological role of DC-SIGN: a tale of mice and men. Trends Immunol. 2013;34(10):482-6.

19. Bongomin F, Gago S, Oladele RO, Denning DW. Global and multi-national prevalence of fungal diseases-estimate precision. J Fungi. 2017;3(4):1-29.

20. Brown GD, Denning DW, Gow NA, Levitz SM, Netea MG, White TC. Hidden killers: human fungal infections. Sci Transl Med. 2012;4(165):165rv13.

21. Padovan AC, Sanson GF, Brunstein A, Briones MR. Fungi evolution revisited: application of the penalized likelihood method to a Bayesian fungal phylogeny provides a new perspective on phylogenetic relationships and divergence dates of Ascomycota groups. J Mol Evol. 2005:60(6):726-35.

22. Benedict K, Jackson BR, Chiller T, Beer KD. Estimation of direct healthcare costs of fungal diseases in the United States. Clin Infect Dis. 2019;68(11):1791-7.

23. Feinberg H, Tso CKW, Taylor ME, Drickamer K, Weis WI. Segmented helical structure of the neck region of the glycan-binding receptor DC-SIGNR. J Mol Biol. 2009;394(4):613-20.

24. Pederson K, Mitchell DA, Prestegard JH. Structural characterization of the DC-SIGN-Lewis(X) complex. Biochemistry. 2014;53(35):5700-9.

25. Serrano-Gómez D, Sierra-Filardi E, Martínez-Nuñez RT, Caparrós E, Delgado R, Muñoz-Fernández MA, et al. Structural requirements for multimerization of the pathogen receptor dendritic cell-specific ICAM3-grabbing non-integrin (CD209) on the cell surface. J Biol Chem. 2008;283(7):3889-903.

26. Mitchell DA, Fadden AJ, Drickamer K. A novel mechanism of carbohydrate recognition by the C-type lectins DC-SIGN and DC-SIGNR. Subunit organization and binding to multivalent ligands. J Biol Chem. 2001;276(31):28939-45.

27. Menon S, Rosenberg K, Graham SA, Ward EM, Taylor ME, Drickamer K, et al. Binding-site geometry and flexibility in DC-SIGN demonstrated with surface force measurements. Proc Natl Acad Sci. 2009;106(28):11524.

28. Tabarani G, Thépaut $M$, Stroebel $D$, Ebel C, Vivès $C$, Vachette $P$, et al. DC-SIGN neck domain is a $\mathrm{pH}$-sensor controlling oligomerization: SAXS and hydrodynamic studies of extracellular domain. J Biol Chem. 2009;284(32):21229-40.

29. Vauquelin G, Charlton SJ. Exploring avidity: understanding the potential gains in functional affinity and target residence time of bivalent and heterobivalent ligands. Br J Pharmacol. 2013;168(8):1771-85.

30. Feinberg H, Guo Y, Mitchell DA, Drickamer K, Weis WI. Extended neck regions stabilize tetramers of the receptors DC-SIGN and DC-SIGNR. J Biol Chem. 2005;280(2):1327-35.

31. Uzarski JS, DiVito MD, Wertheim JA, Miller WM. Essential design considerations for the resazurin reduction assay to noninvasively quantify cell expansion within perfused extracellular matrix scaffolds. Biomaterials. 2017;129:163-75

32. Mummidi S, Catano G, Lam L, Hoefle A, Telles V, Begum K, et al. Extensive repertoire of membrane-bound and soluble dendritic cell-specific ICAM3-grabbing nonintegrin 1 (DC-SIGN1) and DC-SIGN2 isoforms. Interindividual variation in expression of DC-SIGN transcripts. J Biol Chem. 2001;276(35):33196-212.

33. Jullien S, Contrepois A, Sligh JE, Domart Y, Yeni P, Brajtburg J, et al. Study of the effects of liposomal amphotericin B on Candida albicans, Cryptococcus neoformans, and erythrocytes by using small unilamellar vesicles prepared from saturated phospholipids. Antimicrob Agents Chemother 1989:33(3):345-9. 
34. Takemoto K, Yamamoto Y, Ueda Y, Kanazawa K, Yoshida K, Niki Y. Comparative study on the efficacy of liposomal amphotericin B and voriconazole in a murine pulmonary aspergillosis model. Chemotherapy. 2009;55(2):105-13.

35. Johnson EM, Ojwang JO, Szekely A, Wallace TL, Warnock DW. Comparison of in vitro antifungal activities of free and liposome-encapsulated nystatin with those of four amphotericin B formulations. Antimicrob Agents Chemother. 1998;42(6):1412-6.

36. Lewis RE, Liao G, Hou J, Chamilos G, Prince RA, Kontoyiannis DP. Comparative analysis of amphotericin B lipid complex and liposomal amphotericin $B$ kinetics of lung accumulation and fungal clearance in a murine model of acute invasive pulmonary aspergillosis. Antimicrob Agents Chemother. 2007;51(4):1253-8.

37. Andes D, Safdar N, Marchillo K, Conklin R. Pharmacokinetic-pharmacodynamic comparison of amphotericin $B(A M B)$ and two lipid-associated AMB preparations, liposomal $\mathrm{AMB}$ and $\mathrm{AMB}$ lipid complex, in murine candidiasis models. Antimicrob Agents Chemother. 2006;50(2):674-84.

38. Wuyts J, Van Dijck P, Holtappels M. Fungal persister cells: the basis for recalcitrant infections? PLoS Pathog. 2018;14(10):e1007301.

39. Kuipers ME, Nolte-'t Hoen ENM, van der Ham AJ, Ozir-Fazalalikhan A Nguyen DL, de Korne CM, et al. DC-SIGN mediated internalisation of glycosylated extracellular vesicles from Schistosoma mansoni increases activation of monocyte-derived dendritic cells. J Extracell Vesicles. 2020;9(1):1753420.

40. Colmenares $M$, Corbi AL, Turco SJ, Rivas L. The dendritic cell receptor DC-SIGN discriminates among species and life cycle forms of Leishmania. J Immunol. 2004;172(2):1186-90

41. Singh R, Dwivedi SP, Gaharwar US, Meena R, Rajamani P, Prasad T. Recen updates on drug resistance in Mycobacterium tuberculosis. J Appl Microbiol. 2020;128(6):1547-67.

42. Verjee MA. Schistosomiasis: still a cause of significant morbidity and mortality. Res Rep Trop Med. 2019;10:153-63.

43. Meyerhoff A. U.S. Food and Drug Administration approval of Am Bisome (liposomal amphotericin B) for treatment of visceral leishmaniasis. Clin Infect Dis. 1999:28(1):42-8 (discussion 9-51).

44. Gubernator J. Active methods of drug loading into liposomes: recent strategies for stable drug entrapment and increased in vivo activity. Expert Opin Drug Deliv. 2011;8(5):565-80.
45. Ali MS, Hooshmand N, El-Sayed M, Labouta HI. Microfluidics for development of lipid nanoparticles: paving the way for nucleic acids to the clinic. ACS Appl Bio Mater. 2021. https://doi.org/10.1021/acsabm.1c00732

46. Maeki M, Kimura N, Sato Y, Harashima H, Tokeshi M. Advances in microfluidics for lipid nanoparticles and extracellular vesicles and applications in drug delivery systems. Adv Drug Deliv Rev. 2018;128:84-100.

47. Buschmann MD, Carrasco MJ, Alishetty S, Paige M, Alameh MG, Weissman D. Nanomaterial delivery systems for mRNA vaccines. Vaccines. 2021;9(1):65.

48. Rust DM, Jameson G. The novel lipid delivery system of amphotericin B: drug profile and relevance to clinical practice. Oncol Nurs Forum. 1998;25(1):35-48.

49. Allen TM, Hansen CB, Martin FJ, Redemann CT, Yau-Young A. Liposomes containing synthetic lipid derivatives of poly(ethylene glycol) show prolonged circulation half-lives in vivo. Biochem Biophys Acta. 1991;1066(1):29-36.

50. Gref R, Minamitake Y, Peracchia MT, Domb A, Trubetskoy V, Torchilin V, et al. Poly(ethylene glycol)-coated nanospheres: potential carriers for intravenous drug administration. Pharm Biotechnol. 1997;10:167-98.

51. Immordino ML, Dosio F, Cattel L. Stealth liposomes: review of the basic science, rationale, and clinical applications, existing and potential. Int J Nanomedicine. 2006;1(3):297-315.

52. Allen TM, Hansen C. Pharmacokinetics of stealth versus conventional liposomes: effect of dose. Biochim Biophys Acta. 1991;1068(2):133-41.

53. Keppler-Ross S, Douglas L, Konopka JB, Dean N. Recognition of yeast by murine macrophages requires mannan but not glucan. Eukaryot Cell. 2010;9(11):1776-87.

54. Fonzi WA, Irwin MY. Isogenic strain construction and gene mapping in Candida albicans. Genetics. 1993;134(3):717-28.

55. Montone KT. Regulating the T-cell immune response toward the H99 strain of Cryptococcus neoformans. Am J Pathol. 2009:175(6):2255-6.

\section{Publisher's Note}

Springer Nature remains neutral with regard to jurisdictional claims in published maps and institutional affiliations.
Ready to submit your research? Choose BMC and benefit from:

- fast, convenient online submission

- thorough peer review by experienced researchers in your field

- rapid publication on acceptance

- support for research data, including large and complex data types

- gold Open Access which fosters wider collaboration and increased citations

- maximum visibility for your research: over 100M website views per year

At $\mathrm{BMC}$, research is always in progress.

Learn more biomedcentral.com/submissions 